\title{
Clinical outcomes of geriatric patients with COVID-19: review of one-year data
}

\author{
Gulru Ulugerger Avci ${ }^{1}$ (i) $\cdot$ Bahar Bektan Kanat ${ }^{1} \cdot$ Veysel Suzan ${ }^{1} \cdot$ Gunay Can $^{2} \cdot$ Bora Korkmazer $^{3} \cdot$ Ridvan Karaali $^{4}$. \\ Fehmi Tabak ${ }^{4} \cdot$ Sermin Borekci ${ }^{5} \cdot$ Gokhan Aygun $^{6} \cdot$ Hakan Yavuzer $^{1} \cdot$ Alper Doventas $^{1}$
}

Received: 16 October 2021 / Accepted: 2 December 2021 / Published online: 22 January 2022

(C) The Author(s), under exclusive licence to Springer Nature Switzerland AG 2021

\begin{abstract}
Aims In this study, we aimed to reveal mortality rates and factors affecting survival in geriatric patients infected with COVID-19.

Methods This is a retrospective study of 873 geriatric patients with COVID-19 who were hospitalized between March 11, 2020 and March 11, 2021. Demographic, clinical, laboratory data, and treatment options were obtained from electronic medical records. Multivariate logistic regression was used to explore the risk factors for in-hospital death.

Results During the specified period, 643 patients were discharged, and 230 patients died in the hospital. The mean age was $75.08 \pm 7.39$ years (mean \pm SD) and $51.8 \%$ were males. We found that older age $(\geq 85)$, polypharmacy, dyspnea, abnormal thorax computed tomography (CT), lower doses of anticoagulation, and high values of white blood cell, aspartate aminotransferase, C-reactive protein, lactate dehydrogenase, ferritin were associated with a significant increase in mortality $(P<0.001$ for all). Although all of these values were significant in multivariate logistic regression analysis, the most important ones were dyspnea (Odds ratio (OR) 57.916, 95\% confidence interval (CI) 23.439-143.104, $P<0.001$ ), polypharmacy (OR 6.782, 95\% CI 3.082-14.927, $P<0.001$ ), and thorax CT classification (typical; OR 9.633, 95\% CI 2.511-37.122, $P<0.001$ ).

Conclusion Older age, polypharmacy, dyspnea, and abnormal thorax CT were the most significant mortality criteria and in addition appropriate anticoagulant use was associated with reduced mortality. Identifying the risk factors to predict mortality in older adults with COVID-19 is important to treat future cases successfully.
\end{abstract}

Keywords COVID- $19 \cdot$ Geriatrics $\cdot$ Hospitalized patients $\cdot$ Mortality $\cdot$ Risk factors

Gulru Ulugerger Avci

gulru83@gmail.com

1 Division of Geriatric Medicine, Department of Internal Medicine, Cerrahpasa Medical Faculty, Istanbul UniversityCerrahpasa, Istanbul, Turkey

2 Department of Public Health, Cerrahpasa Medical Faculty, İstanbul University-Cerrahpaşa, İstanbul, Turkey

3 Department of Radiology, Cerrahpasa Medical Faculty, İstanbul University-Cerrahpaşa, İstanbul, Turkey

4 Department of Infectious Diseases, Cerrahpasa Medical Faculty, İstanbul University-Cerrahpaşa, İstanbul, Turkey

5 Department of Pulmonary Diseases, Cerrahpasa Medical Faculty, İstanbul University-Cerrahpaşa, İstanbul, Turkey

6 Department of Medical Microbiology, Cerrahpasa Medical Faculty, İstanbul University-Cerrahpaşa, İstanbul, Turkey

\section{Background}

Coronavirus disease 2019 (COVID-19), an acute infectious disease caused by the SARS-CoV-2 virus, is a global epidemic [1]. COVID-19's first case was detected in Turkey on March 11th, 2020. Six months after the first case, the total number of COVID-19 patients was reported to be 288.126 , and the total number of deaths due to SARSCoV-2 was 6951. On March 11th, 2021, 2.835 .989 people have been diagnosed as COVID-19 positive, and 29.290 people have lost their lives. In Turkey, at the beginning of the pandemic, the government introduced several restrictions. First, schools and all public gathering places were closed, and a permanent lockdown for the elderly and with chronic illnesses was declared, followed by weekend curfews. The Ministry of Health gave an emergency use authorization for CoronaVac on Jan 13, 2021. An immediate vaccination program was started initially for healthcare workers and in the 
following months for the public, especially for older adults (aged $\geq 65$ years).

The disease presents a clinical picture ranging from asymptomatic to severe respiratory failure, sepsis, and death [2]. As it is known, patients over the age of 65 are very frail due to their accompanying diseases and physiological changes [3]. Studies have revealed that the elderly are in the risk group for the disease [4]. The course of the disease in the elderly may differ from the young. High fatality rates are observed in the elderly COVID-19 patients [5].

In this study, we aimed to reveal the factors affecting the mortality and survival of patients aged 65 and over who were hospitalized due to COVID-19 for 1 year in our hospital's inpatient services and intensive care units by comparing the first and the second 6 months.

\section{Methods}

\section{Study population and design}

Patients aged 65 and over who were discharged or died after being followed up in the COVID service and intensive care units of Istanbul University Cerrahpaşa Medical Faculty Hospital between 11 March 2020 and 11 March 2021 with the diagnosis of COVID-19 were included in the study. This study was approved by the Ethics Committee of Istanbul University-Cerrahpaşa, Cerrahpaşa Medical Faculty (35115-19.02.2021). An informed consent was obtained from all participants who were given assurances that their data would be treated confidentially.

Demographic data, symptoms at presentation, altered states of consciousness, comorbidity, medication use, vital sign, results of blood tests were extracted from electronic medical records and retrospectively reviewed and analyzed. Initial reference levels of hematocrit (Hct), neutrophil, lymphocyte, monocytes, aspartate aminotransferase (AST), alanine aminotransferase (ALT), urea, creatinine, lactate dehydrogenase (LDH), C-reactive protein (CRP), ferritin, fibrinogen, and D-dimer values; the highest values of CRP, fibrinogen, urea, creatinine, D-dimer, $\mathrm{LDH}$, and ferritin during the course of hospitalization were obtained from the electronic information system. The number of days of hospitalization, initial oxygen needs during hospital admission, and the lowest oxygen saturation $\left(\mathrm{SpO}_{2}\right)$ values were recorded in intensive care units and inpatient clinics. In addition, COVID-19 polymerase chain reaction (PCR) test results, chest $\mathrm{CT}$ manifestations and drug regimens used in the treatment of COVID-19 were accessed. Chest CT manifestations were staged by a radiologist in accordance with the reporting recommendations of the Society of Radiology North American Expert Consensus. The findings in the images were classified as typical, atypical, indeterminate, or negative [6]. The diagnosis of death due to COVID-19 disease was made with PCR positivity or the presence of thoracic CT findings. The use of five or more drugs on admission was considered polypharmacy [7, 8]. Patients were divided into two groups according to the hospitalization date due to 1 st and 2nd 6 month periods. The length of hospital stay for the two periods were specified. The length of stay for the discharged and deceased patients during the 1 st and 2 nd 6 month period was analyzed. The mortality and discharge rates of the patients were examined by comparing the 1 st and 2nd 6 months.

\section{Statistical analysis}

We expressed continuous variables as medians and interquartile ranges. Categorical variables were given as counts and percentages. A comparison of categorical variables between the discharged and deceased groups was performed using Pearson's $\chi^{2}$ test with continuity correction or Fisher's exact test, where appropriate. Student's $t$ test and The Mann-Whitney $U$ test were used to compare differences in continuous variables between the two groups because they were all non-normally distributed. Multivariable logistic regression modeling was used to explore independent risk factors for death. Regression analysis was performed for parameters associated with mortality within their own groups (comorbidities, symptoms, etc.). Multivariate regression analysis was also performed for the parameters that were significant in these analyses. Continuous variables were treated as continuous measures in the model. Statistical analyses were performed using SPSS version 21.0 (IBM Corporation, Armonk, NY, USA). Differences were considered to be statistically significant when two-sided $\mathrm{P}$ values were less than 0.05 .

\section{Results}

Eight hundred seventy-three patients, 452 males and 421 females, were included in the study. Mortality was $26.3 \%(n: 230)$ among the geriatric COVID-19 patients. Although the mortality rate in man was $58.3 \%(n: 134)$, it was $41.7 \%$ (n:96) in women. The mortality rate of men was higher than that of women $(P: 0.022)$. The patients were divided into three age groups ranging from 65 to 74 ( $n: 466), 75-84$ ( $n: 296)$, and 85 or more ( $n: 111)$ years. The mortality rate was found to be high in the 85 years and older group (OR 6.054, 95\% CI 2.719-13.479, $P:<0.001$ ). Whether the risk of death actually rose above 85 or any other age threshold was confirmed by Cubic spline regression and it was observed that there was an increase over the age of 85 (Fig. 1). When we re-analyze the age groups with 5 -year intervals rather than 10 years, the mortality 
Fig. 1 Cubic spline regression analysis of death and age

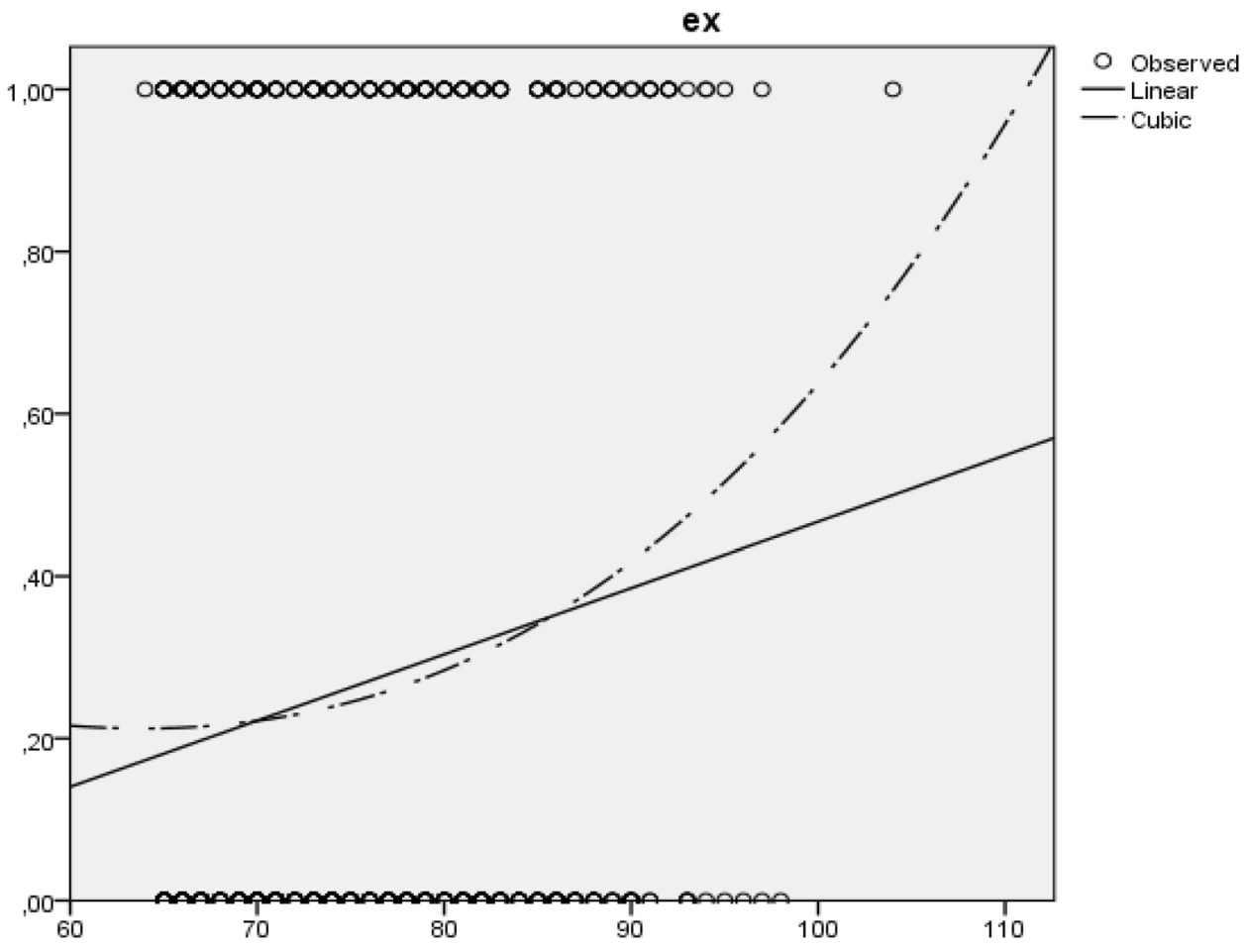

Age rate was $21 \%$ under the age of $70,22 \%$ in the age group of $70-74,31 \%$ in the age group of $75-79,25 \%$ in the age group of $80-84,37 \%$ in the age group of $85-89$ and $50 \%$ in the 90 years and over group. In addition ROC analysis was performed and the maximum Youden Index (Sensitivity + specificity) value was reached at 84 (Fig. 2).

As shown in Table 1, the most common comorbidities were hypertension (69.8\%), type 2 diabetes mellitus $(38.4 \%)$, coronary artery disease (CAD; $25.3 \%)$. Although we found no relationship in terms of comorbidities, some epidemiological studies have shown that hypertension was associated with increased mortality and morbidity in COVID-19 patients [9]. On the other hand, in our study malignancy, congestive heart failure, and chronic renal disease were found to be more common in patients who died (respectively, $P:<0.001,0.001,0.001$ ). Polypharmacy was present in $71.8 \%$ of the patients and was significantly higher in the patients who died (OR 6.782, 95\% CI 3.082-14.927, P: <0.001). The mortality was found to be significantly higher in those who did not use ARB (P: 0.004). Common symptoms were fever $(23.4 \%)$, cough (24.6\%), and shortness of breath (45.9\%) (Table 1). Mortality rates were higher in patients with dyspnea (OR 57.916, 95\% CI 23.439-143.104, P: $<0.001)$. Mortality rates were found to be higher in those who did not have cough, who did not express headache or myalgia complaint (respectively, $P$ : 0.001, 0,015, and 0.040). Mortality rates

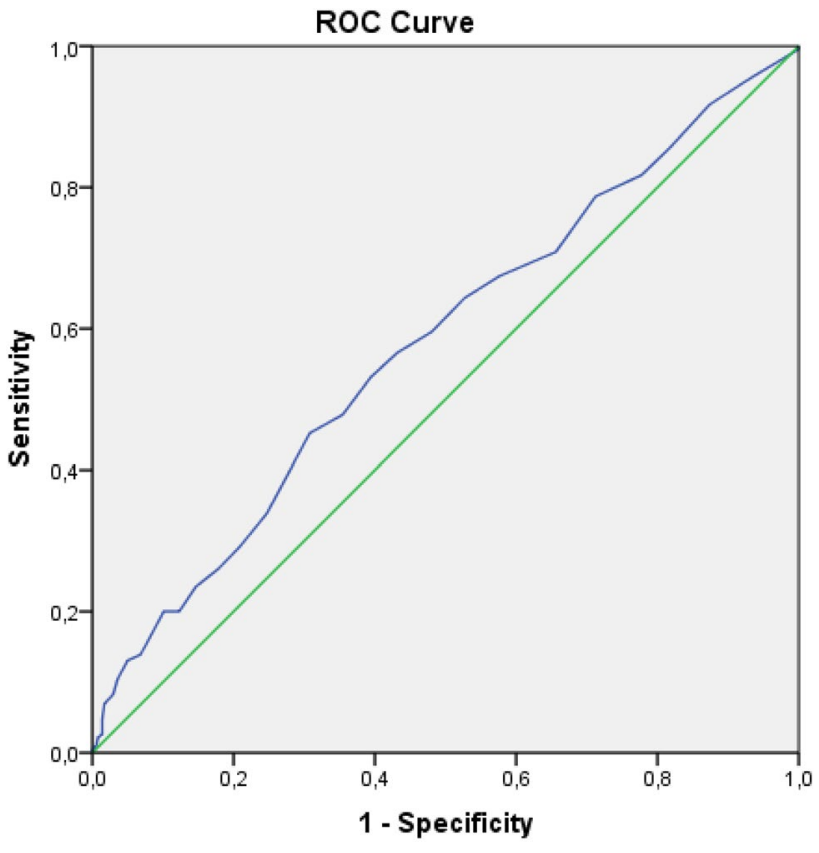

Diagonal segments are produced by ties.

Fig. 2 Receiver-operating characteristic (ROC) curve analysis of age and mortality. Area under the ROC curve (AUC) for age 0.579, $(P<0.001,95 \%$ CI $0.535-0.623)$ 
Table 1 Demographics and clinical presentation in patients with COVID-19 pneumonia

\begin{tabular}{|c|c|c|c|c|}
\hline Characteristics & All patients & Recovery and discharge & Death & $P$ value \\
\hline$n$ & 873 & $643(\% 73.7)$ & $230(\% 26.3)$ & \\
\hline Age, mean \pm SD & $75.08( \pm 7.39)$ & $74.47( \pm 7.03)$ & $76.77( \pm 8.1)$ & $<0.001$ \\
\hline \multicolumn{5}{|l|}{ Age, groups, $n(\%)$} \\
\hline $65-74$ & $466(53.4 \%)$ & $366(56.9 \%)$ & $100(43.5 \%)$ & \multirow{3}{*}{$<0.001$} \\
\hline $75-84$ & $296(33.9 \%)$ & $212(33.0 \%)$ & $84(36.5 \%)$ & \\
\hline$\geq 85$ & $111(12.7 \%)$ & $65(10.1 \%)$ & $46(20.0 \%)$ & \\
\hline \multicolumn{5}{|l|}{ Sex } \\
\hline Male $(\%)$ & $452(51.8 \%)$ & $318(49.5 \%)$ & $134(58.3 \%)$ & \multirow[t]{2}{*}{0.022} \\
\hline Female $(\%)$ & $421(48.2 \%)$ & $325(50.5 \%)$ & $96(41.7 \%)$ & \\
\hline \multicolumn{5}{|l|}{ Comorbidity $n(\%)$} \\
\hline Any & $781(89.5 \%)$ & $565(87.9 \%)$ & $216(93.9 \%)$ & 0.01 \\
\hline Hypertension & $609(69.8 \%)$ & $451(70.1 \%)$ & $158(68.7 \%)$ & 0.682 \\
\hline Diabetes & $335(38.4 \%)$ & $235(36.5 \%)$ & $100(43.5 \%)$ & 0.064 \\
\hline Malignancy & $121(13.9 \%)$ & $67(10.4 \%)$ & $54(23.5 \%)$ & $<0.001$ \\
\hline COPD & $186(21.3 \%)$ & $138(21.5 \%)$ & $48(20.9 \%)$ & 0.851 \\
\hline $\mathrm{CHF}$ & $96(11.0 \%)$ & $57(8.9 \%)$ & $39(17.0 \%)$ & $<0.001$ \\
\hline CAD & $221(25.3 \%)$ & $162(25.2 \%)$ & $59(25.7 \%)$ & 0.891 \\
\hline Chronic renal disease & $93(10.7 \%)$ & $55(8.6 \%)$ & $38(16.5 \%)$ & $<0.001$ \\
\hline Chronic liver disease & $4(0.5 \%)$ & $4(0.6 \%)$ & $0(0 \%)$ & 0.578 \\
\hline Cerebrovascular disease & $88(10.1 \%)$ & $61(9.5 \%)$ & $27(11.7 \%)$ & 0.33 \\
\hline Dementia & $81(9.3 \%)$ & $54(8.4 \%)$ & $27(11.7 \%)$ & 0.134 \\
\hline Polypharmacy & $627(71.8 \%)$ & $415(64.5 \%)$ & $212(92.2 \%)$ & $<0.001$ \\
\hline $\begin{array}{l}\text { Number of drugs used, } \\
\text { mean } \pm \text { SD }\end{array}$ & $6.97( \pm 3.46)$ & $6.38( \pm 3.3)$ & $8.6( \pm 3.3)$ & $<0.001$ \\
\hline ACEI, $n(\%)$ & $180(20.6 \%)$ & $138(21.5 \%)$ & $42(18.3 \%)$ & 0.303 \\
\hline $\mathrm{ARB}, n(\%)$ & $238(27.3 \%)$ & $192(29.9 \%)$ & $46(20.0 \%)$ & 0.004 \\
\hline \multicolumn{5}{|l|}{ Presence of symptoms, $n(\%)$} \\
\hline Fever & $204(23.4 \%)$ & $150(23.3 \%)$ & $54(23.5 \%)$ & 0.963 \\
\hline Cough & $215(24.6 \%)$ & $177(27.5 \%)$ & $38(16.5 \%)$ & $<0.001$ \\
\hline Fatigue & $182(20.8 \%)$ & $143(22.2 \%)$ & $39(17.0 \%)$ & 0.091 \\
\hline Myalgia & $55(6.3 \%)$ & $47(7.3 \%)$ & $8(3.5 \%)$ & 0.04 \\
\hline Dsypnea & $401(45.9 \%)$ & $179(27.8 \%)$ & $222(96.5 \%)$ & $<0.001$ \\
\hline Sputum & $22(2.5 \%)$ & $17(2.6 \%)$ & $5(2.2 \%)$ & 0.696 \\
\hline Headache & $15(1.7 \%)$ & $15(2.3 \%)$ & $0(0 \%)$ & 0.015 \\
\hline Loss of taste and smell & $11(1.3 \%)$ & $9(1.4 \%)$ & $2(0.9 \%)$ & 0.737 \\
\hline Diarrhea & $32(3.7 \%)$ & $26(4.0 \%)$ & $6(2.6 \%)$ & 0.320 \\
\hline Nausea/vomiting & $50(5.7 \%)$ & $40(6.2 \%)$ & $10(4.3 \%)$ & 0.294 \\
\hline Altered states of consciousness & $195(22.3 \%)$ & $42(6.5 \%)$ & $153(66.5 \%)$ & $<0.001$ \\
\hline
\end{tabular}

$C A D$ coronary artery disease; $C H F$ congestive heart failure; $C O P D$ chronic obstructive pulmonary disease; $A C E I$ angiotensin converting enzyme inhibitor; $A R B$ angiotensin receptor blocker

Significant $P$ values are in bold were also higher in patients with altered states of consciousness $(P:<0.001)$.

This study also investigated possible relationships between mortality and laboratory values. As shown Table 2, patients having lower lymphocyte, hematocrit levels and higher white blood cell count at the time of admission were found to have higher mortality rate (respectively, $P$ : 0.031 , 0.010 and $<0.001)$. AST and ALT values on admission were significantly higher $(P<0.001$ for both of them). Urea and creatinine levels on admission and the highest creatinine values were higher in the patients who died (respectively, $P:<0.001,0.001,<0.001)$. CRP, ferritin, D-dimer and LDH on admission and their highest values were associated with mortality $(P<0.001$ for all). Fibrinogen levels on admission and the highest values were higher in the patients who died (respectively, $P$ : $0.005,<0.001$ ). 
Table 2 Laboratory findings of patients with COVID-19 pneumonia

\begin{tabular}{llllr}
\hline Laboratory results, mean \pm SD & All patients & Recovery and discharge & Death & $P$ value \\
\hline Hemotocrit $\%$ & $34.3( \pm 5.8)$ & $34.6( \pm 5.6)$ & $33.4( \pm 6.0)$ & $\mathbf{0 . 0 1 0}$ \\
WBC, $10^{\wedge} 3 / \mu \mathrm{L}$ & $6.4( \pm 5.1)$ & $5.4( \pm 3.7)$ & $9.0( \pm 7.1)$ & $<\mathbf{0 . 0 0 1}$ \\
Lymphocyte, $10^{\wedge} 3 / \mu \mathrm{L}$ & $1.35( \pm 4.1)$ & $1.5( \pm 4.7)$ & $0.8( \pm 0.6)$ & $\mathbf{0 . 0 3 1}$ \\
AST, IU/L & $54.9( \pm 186.8)$ & $34.4( \pm 31.3)$ & $112.4( \pm 354.5)$ & $<\mathbf{0 . 0 0 1}$ \\
ALT, IU/L & $42.6( \pm 157.1)$ & $26.0( \pm 34.9)$ & $88.9( \pm 296.1)$ & $<\mathbf{0 . 0 0 1}$ \\
Urea, mg/L & $58.3( \pm 41.0)$ & $52.2( \pm 34.6)$ & $75.2( \pm 51.6)$ & $<\mathbf{0 . 0 0 1}$ \\
Highest Urea, mg/L & $212.9( \pm 100.9)$ & $212.6( \pm 93.7)$ & $213.8( \pm 118.9)$ & 0.880 \\
Creatinine, mg/L & $1.37( \pm 1.26)$ & $1.28( \pm 1.18)$ & $1.61( \pm 1.44)$ & $\mathbf{0 . 0 0 1}$ \\
Highest creatinine, mg/L & $1.89( \pm 2.94)$ & $1.65( \pm 3.23)$ & $2.54( \pm 1.77)$ & $<\mathbf{0 . 0 0 1}$ \\
Ferritin, ng/mL & $553.0( \pm 561.6)$ & $430.6( \pm 463.0)$ & $895.2( \pm 663.4)$ & $<\mathbf{0 . 0 0 1}$ \\
Highest ferritin, $\mathrm{ng} / \mathrm{mL}$ & $851.6( \pm 842.7)$ & $663.9( \pm 584.2)$ & $1459.1( \pm 1114.5)$ & $<\mathbf{0 . 0 0 1}$ \\
D-dimer, $\mathrm{mg} / \mathrm{L}$ & $3.84( \pm 9.82)$ & $2.17( \pm 4.85)$ & $8.52( \pm 16.51)$ & $<\mathbf{0 . 0 0 1}$ \\
Highest D-dimer, mg/L & $8.69( \pm 15.24)$ & $5.63( \pm 10.97)$ & $17.27( \pm 21.16)$ & $<\mathbf{0 . 0 0 1}$ \\
LDH, IU/L & $371.6( \pm 284.9)$ & $316.8( \pm 161.1)$ & $524.6( \pm 451.9)$ & $<\mathbf{0 . 0 0 1}$ \\
Highest LDH, IU/L & $584.6( \pm 446.8)$ & $484.8( \pm 247.2)$ & $863.3( \pm 694.8)$ & $<\mathbf{0 . 0 0 1}$ \\
CRP, mg/L & $87.7( \pm 76.5)$ & $70.4( \pm 65.6)$ & $136.4( \pm 83.7)$ & $<\mathbf{0 . 0 0 1}$ \\
Highest CRP, mg/L & $133.3( \pm 105.8)$ & $99.1( \pm 78.7)$ & $229.4( \pm 113.0)$ & $<\mathbf{0 . 0 0 1}$ \\
Fibrinogen, mg/dL & $507.0( \pm 216.3)$ & $494.7( \pm 223.1)$ & $541.2( \pm 192.4)$ & $\mathbf{0 . 0 0 5}$ \\
Highest fibrinogen, mg/dL & $622.3( \pm 176.5)$ & $599.5( \pm 162.9)$ & $685.9( \pm 196.9)$ & $<\mathbf{0 . 0 0 1}$ \\
\hline
\end{tabular}

$W B C$ white blood cell; $L D H$ lactate dehydrogenase; $C R P$ C-reactive protein; INR international normalized ratio; $A S T$ aspartate aminotransferase; $A L T$ alanine aminotransferase

Significant $P$ values are in bold
Clinical findings and treatment modalities in patients with COVID-19 pneumonia are shown in Table 3. Two hundred ninety-six of the patients were hospitalized in the intensive care unit and five hundred seventy-seven in the inpatient clinics. Mortality rates were found to be high in patients hospitalized in the intensive care unit $(P:<0.001)$. Also, vital signs of patients, such as low saturation, high pulse, and low blood pressure were associated with death $(P:<0.001$ for all). The COVID PCR tests were positive in $67.5 \%(n: 589)$ of the patients and were positive in $74.8 \%(n: 172)$ of those who died ( $P: 0.006)$. Typical COVID manifestations were positive in chest CTs in $57.0 \%$ of the patients and mortality was high $(P<0.001)$. In multivariate regression analysis, typical, atypical, and indeterminate covid manifestations in chest CT were the factors predicting mortality (respectively, $P:<0.001,0.009,0.017)$. Compared with those with negative chest CT manifestations, mortality was found to be 9.6 times higher in patients with typical chest CT manifestations, 7.9 times higher in atypical patients, and 6.6 times higher in patients with indeterminate chest CT manifestations. Mortality was found to be high in patients in need for oxygen therapy $(P<0.001)$. The most used drugs in medical treatment were $87.7 \%$ anticoagulants, $75.4 \%$ favipiravir, $40.3 \%$ corticosteroids. It was found that patients who used anticoagulants had lower mortality rate $(P:<0.001)$. According to the multivariate logistic regression results, anticoagulant therapy was associated with a lower risk of death (OR 0.336, 95\% CI 0.132-0.855, P:0.022). In contrast, the use of corticosteroids was found to be higher in the patients who died $(P:<0.001)$. However, steroids were given especially to severe patients with cytokine storm.

Clinical findings, treatment methods, and presenting symptoms of the patients hospitalized in the first 6 months and the last 6 months are shown in Table 4. Among the symptoms, cough and diarrhea complaints were more common in the first 6 months (respectively, $P$ : 0.030, 0.024); In the second 6 months altered states of consciousness, fatigue, dyspnea, and myalgia were more common (respectively, $P:<0.001,<0.001,0.028,0.001)$. In the second 6 months, the blood pressure and saturation of the patients were lower. COVID PCR positivity and typical COVID manifestations in chest $\mathrm{CT}$ were significantly higher in the second 6 months $(P:<0.001)$. It was observed that the use of hydroxychloroquine, azithromycin, oseltamivir, lopinavir/ ritonavir was higher in the first 6 months $(P:<0.001)$. In the second 6 months, the use of favipiravir, corticosteroids and anticoagulants was higher $(P:<0.001)$. The death rate and hospitalization of the intensive care unit patients were higher in the second 6 months (respectively, $P: 0.005,0.011$ ). The mean hospital stay was 10.3 days in the first 6 months and 10.8 days in the following 6 months. In terms of the mean length of stay no significant difference was found between the discharged and deceased group. The mean length of hospital stay was found to be significantly higher in patients 
Table 3 Clinical findings and treatment modalities of patients with COVID-19 pneumonia

\begin{tabular}{|c|c|c|c|c|}
\hline Clinical findings and treatment modalities & All patients & Recovery and discharge & Death & $P$ value \\
\hline$n$ & 873 & $643(\% 73.7)$ & $230(\% 26.3)$ & \\
\hline Total hospitalized days numbers, mean \pm SD & $10.5( \pm 8.2)$ & $10.3( \pm 8.1)$ & $11.2( \pm 8.4)$ & 0.161 \\
\hline $\begin{array}{l}\text { Hospitalized days numbers in intensive care unit, } \\
\text { mean } \pm \text { SD }\end{array}$ & $9.4( \pm 8.9)$ & $10.2( \pm 12.0)$ & $9.2( \pm 7.8)$ & 0.431 \\
\hline Patients hospitalized in the intensive care unit & $296(33.9 \%)$ & $72(11.2 \%)$ & $224(97.4 \%)$ & $<0.001$ \\
\hline $\mathrm{SpO} 2 \%$ on admission, mean $\pm \mathrm{SD}$ & $92.6( \pm 4.6)$ & $93.6( \pm 3.8)$ & $89.6( \pm 5.4)$ & $<0.001$ \\
\hline The lowest $\mathrm{SpO} 2 \%$, mean $\pm \mathrm{SD}$ & $87.3( \pm 8.8)$ & $91.2( \pm 4.5)$ & $76.3( \pm 8.6)$ & $<0.001$ \\
\hline \multicolumn{5}{|l|}{ Blood pressure on admission, $n(\%)$} \\
\hline $\begin{array}{l}>90 / 60 \\
\leq 90 / 60\end{array}$ & $\begin{array}{l}835(95.6 \%) \\
38(4.4 \%)\end{array}$ & $\begin{array}{l}639(99.4 \%) \\
4(0.6 \%)\end{array}$ & $\begin{array}{l}196(85.2 \%) \\
34(14.8 \%)\end{array}$ & $<0.001$ \\
\hline Pulse rate on admission, mean $\pm S D$ & $86( \pm 20)$ & $82( \pm 17)$ & $97( \pm 24)$ & $<0.001$ \\
\hline COVID PCR positive, $n(\%)$ & $589(67.5 \%)$ & $417(64.9 \%)$ & $172(74.8 \%)$ & 0.006 \\
\hline \multicolumn{5}{|l|}{ Thorax CT Classification, $n(\%)$} \\
\hline $\begin{array}{l}0 \text { (negative) } \\
1 \text { (atypical) } \\
2 \text { (indeterminate) } \\
3 \text { (typical) }\end{array}$ & $\begin{array}{l}90(10 \%) \\
139(16 \%) \\
150(17 \%) \\
494(57 \%)\end{array}$ & $\begin{array}{l}84(13.1 \%) \\
106(16.5 \%) \\
116(18.0 \%) \\
337(52.4 \%)\end{array}$ & $\begin{array}{l}6(2.6 \%) \\
33(14.3 \%) \\
34(14.8 \%) \\
157(68.3 \%)\end{array}$ & $<0.001$ \\
\hline Oxygen treatment, $n(\%)$ & $550(63 \%)$ & $324(50.4 \%)$ & $226(98.3 \%)$ & $<0.001$ \\
\hline \multicolumn{5}{|l|}{ COVID treatment, $n(\%)$} \\
\hline $\begin{array}{l}\text { Hydroxychloroquine } \\
\text { Azithromycin } \\
\text { Lopinavir/ritonavir } \\
\text { Oseltamivir } \\
\text { Tocilizumab } \\
\text { Favipiravir } \\
\text { Corticosteroids } \\
\text { Anticoagulants }\end{array}$ & $\begin{array}{l}280(32.1 \%) \\
194(22.2 \%) \\
17(1.9 \%) \\
163(18.7 \%) \\
113(12.9 \%) \\
658(75.4 \%) \\
352(40.3 \%) \\
766(87.7 \%)\end{array}$ & $\begin{array}{l}214(33.3 \%) \\
154(24.0 \%) \\
14(2.2 \%) \\
123(19.1 \%) \\
88(13.7 \%) \\
483(75.1 \%) \\
207(32.2 \%) \\
582(90.5 \%)\end{array}$ & $\begin{array}{l}66(28.7 \%) \\
40(17.4 \%) \\
3(1.3 \%) \\
40(17.4 \%) \\
25(10.9 \%) \\
175(76.1 \%) \\
145(63.0 \%) \\
184(80.0 \%)\end{array}$ & $\begin{array}{l}0.201 \\
\mathbf{0 . 0 4 0} \\
0.581 \\
0.562 \\
0.275 \\
0.769 \\
<\mathbf{0 . 0 0 1} \\
<\mathbf{0 . 0 0 1}\end{array}$ \\
\hline
\end{tabular}

$\mathrm{SpO} 2$ oxygen saturation; $C O V I D P C R$ Coronavirus disease polymerase chain reaction; $C T$ computerized tomography

Significant $P$ values are in bold

who died in the first 6 months $(P: 0.015)$, no significant difference was found in the second period.

In multivariate logistic regression analysis to detect the factors predicting mortality among older patients with COVID-19, age groups; chest CT classification; polypharmacy; dyspnea; lower doses of anticoagulation; AST; the highest values of CRP, LDH, and ferritin; the lowest values of lymphocyte and the highest values of white blood cell at the time of admission were independently associated with mortality (Table 5).

\section{Discussion}

This study showed that older age, polypharmacy, dyspnea, thorax CT classification, lower doses of anticoagulation, the laboratory parameters AST, CRP, LDH, ferritin, lymphocyte, and white blood cells were independent risk factors associated with a fatal outcome. These results have some similarities but also differences from the previous studies. In our study, mortality was $26.3 \%$ (n:230) among the geriatric
COVID-19 patients. Furthermore in another retrospective study, 709 patients who were over 18 years old and received inpatient treatment for COVID-19 disease at our hospital between March 16, 2020 and June 18, 2020 was enrolled. Of the 709 patients treated for COVID-19, 75 (11\%) died and 634 survived. The mortality risk increased 4.07 -fold in patients aged between 55 and 64, 7.85-fold in patients aged 65 and 74, and 11.95-fold in patients aged 75 or older. The older age, specific comorbidities (cancer, heart failure, chronic renal failure), dyspnea, lower levels of oxygen saturation and hematocrit, higher levels of $\mathrm{C}$-reactive protein, aspartate aminotransferase, and ferritin were independent risk factors for mortality. [10].

Since the beginning of the pandemic, older adults have been severely affected by the consequences of COVID- 19 . According to the Centers for Disease Control and Prevention (CDC), people over age 65 were responsible for $31 \%$ of COVID-19 infections, $45 \%$ of hospitalizations, and $80 \%$ of deaths caused by COVID-19 [11]. Many studies have shown that mortality increases with age [12-14]. In a study of 72,314 cases in China, the overall mortality rate was $2.3 \%$; 
Table 4 Clinical findings, treatment methods and presentation symptoms of the patients hospitalized in the first and the second 6 months

\begin{tabular}{|c|c|c|c|}
\hline $\begin{array}{l}\text { Clinical findings, treatment methods and presenta- } \\
\text { tion symptoms }\end{array}$ & First 6 months & Last 6 months & $P$ value \\
\hline$n$ & $403(46.2 \%)$ & $470(53.8 \%)$ & \\
\hline \multicolumn{4}{|l|}{ Sex } \\
\hline Male $(\%)$ & $206(51.1 \%)$ & $246(52.3 \%)$ & \multirow[t]{2}{*}{0.718} \\
\hline Female (\%) & $197(48.9 \%)$ & $224(47.4 \%)$ & \\
\hline \multicolumn{4}{|l|}{ Age, groups, $n(\%)$} \\
\hline $65-74$ & $209(51.9 \%)$ & $257(54.7 \%)$ & \multirow[t]{3}{*}{0.693} \\
\hline $75-84$ & $142(35.2 \%)$ & $154(32.8 \%)$ & \\
\hline$\geq 85$ & $52(12.9 \%)$ & $59(12.6 \%)$ & \\
\hline \multicolumn{4}{|l|}{ Presence of symptoms, $n(\%)$} \\
\hline Fever & $91(22.6 \%)$ & $113(24.0 \%)$ & 0.611 \\
\hline Cough & $113(28 \%)$ & $102(21.7 \%)$ & $\mathbf{0 . 0 3 0}$ \\
\hline Fatigue & $61(15.1 \%)$ & $121(25.7 \%)$ & $<0.001$ \\
\hline Dsypnea & $169(41.9 \%)$ & $232(49.4 \%)$ & 0.028 \\
\hline Sputum & $13(3.2 \%)$ & $9(1.9 \%)$ & 0.218 \\
\hline Headache & $5(1.2 \%)$ & $10(2.1 \%)$ & 0.315 \\
\hline Loss of taste and smell & $5(1.2 \%)$ & $6(1.3 \%)$ & 0.962 \\
\hline Myalgia & $14(3.5 \%)$ & $41(8.7 \%)$ & 0.001 \\
\hline Diarrhea & $21(5.2 \%)$ & $11(2.3 \%)$ & 0.024 \\
\hline Nausea/vomiting & $25(6.2 \%)$ & $25(5.3 \%)$ & 0.575 \\
\hline Altered states of consciousness & $67(16.6 \%)$ & $128(27.2 \%)$ & $<0.001$ \\
\hline \multicolumn{4}{|l|}{ Blood pressure on admission, $n(\%)$} \\
\hline$>90 / 60$ & $394(97.8 \%)$ & $441(93.8 \%)$ & \multirow[t]{2}{*}{0.004} \\
\hline$\leq 90 / 60$ & $9(2.2 \%)$ & $29(6.2 \%)$ & \\
\hline $\mathrm{SpO} 2 \%$ on admission, mean $\pm \mathrm{SD}$ & $92.7( \pm 4.7)$ & $92.4( \pm 4.5)$ & 0.328 \\
\hline The lowest $\mathrm{SpO} 2 \%$, mean $\pm \mathrm{SD}$ & $88.1( \pm 7.8)$ & $86.5( \pm 9.5)$ & 0.008 \\
\hline COVID PCR positive, $n(\%)$ & $190(47 \%)$ & $396(84 \%)$ & $<0.001$ \\
\hline \multicolumn{4}{|l|}{ Thorax CT Classification, $n(\%)$} \\
\hline 0 (negative) & $52(12.9 \%)$ & $38(8.1 \%)$ & \multirow[t]{4}{*}{$<0.001$} \\
\hline 1 (atypical) & $71(17.6 \%)$ & $68(14.5 \%)$ & \\
\hline 2 (indeterminate) & $88(21.8 \%)$ & $62(13.2 \%)$ & \\
\hline 3 (typical) & $192(47.6 \%)$ & $302(64.3 \%)$ & \\
\hline Oxygen treatment, $n(\%)$ & $261(64.8 \%)$ & $289(61.5 \%)$ & 0.318 \\
\hline \multicolumn{4}{|l|}{ COVID treatment, $n(\%)$} \\
\hline Tocilizumab & $99(51.03 \%)$ & $95(48.9 \%)$ & 0.238 \\
\hline Favipiravir & $253(62.8 \%)$ & $405(86.2 \%)$ & $<0.001$ \\
\hline Corticosteroids & $53(13.2 \%)$ & $299(63.6 \%)$ & $<0.001$ \\
\hline Anticoagulants & $325(80.6 \%)$ & $441(93.8 \%)$ & $<0.001$ \\
\hline Patients hospitalized in the intensive care unit & $119(29.5 \%)$ & $177(37.7 \%)$ & 0.011 \\
\hline Death & $88(21.8 \%)$ & $142(30.2 \%)$ & $<0.001$ \\
\hline
\end{tabular}

Significant $P$ values are in bold however, this rate was $8 \%$ in patients aged $70-79$ years and $14.5 \%$ in $\geq 80$ years. [15] Similarly in our study, mortality was higher in patients aged 85 years and older $(41.4 \%)$.

In a large-scale study involving 1663 patients, the mortality rate in men was higher than in women, similar to our study [16]. Malignancy is also an independent risk factor for mortality $[17,18]$. This result may be due to the impaired immunity and inflammatory response in cancer patients. In our study, mortality was found to be higher in patients with malignancy. There is no research in the literature investigating the effect of polypharmacy on the prognosis of COVID19. Polypharmacy was significantly higher in patients who died in our study. It was determined as one of the parameters predicting the mortality rate in multivariate regression analysis. Angiotensin converting enzyme 2 (ACE2) is a core receptor for viral entry of SARSCoV-2 [19, 20]. Therefore, at the beginning of the pandemic the use of ACEI and ARB was thought to have a role in the pathogenesis of COVID19 [21]. However, studies have shown that the use of ACEI and ARBs regulated RAAS homeostasis in severe COVID19 [22]. Additionally, ARB has been shown to reduce lung fibrosis, hypertrophy, and the release of pro-inflammatory cytokines; as well as improving heart function [23]. As for the effects of ARBs in COVID-19, it was shown to reduce 
Table 5 Multivariate logistic regression analysis of risk factors for mortality in COVID-19

\begin{tabular}{|c|c|c|}
\hline Variable & Odds ratio $(95 \% \mathrm{CI})$ & $P$ value \\
\hline \multicolumn{3}{|l|}{ Age, groups, $n(\%)$} \\
\hline $65-74$ & 1 & \multirow{3}{*}{$\begin{array}{l}0.277 \\
<\mathbf{0 . 0 0 1}\end{array}$} \\
\hline $75-84$ & $1.400(0.763-2.570)$ & \\
\hline$\geq 85$ & $6.054(2.719-13.479)$ & \\
\hline \multicolumn{3}{|l|}{ Sex } \\
\hline Female & 1 & \multirow[t]{2}{*}{0.522} \\
\hline Male & $0.832(0.474-1.460)$ & \\
\hline Malignancy & $1.222(0.579-2.582)$ & 0.599 \\
\hline $\mathrm{CHF}$ & $1.212(0.542-2.712)$ & 0.640 \\
\hline Chronic renal disease & $0.956(0.408-2.243)$ & 0.918 \\
\hline Polypharmacy & $6.782(3.082-14.927)$ & $<0.001$ \\
\hline Dsypnea & $57.916(23.439-143.104)$ & $<0.001$ \\
\hline $\mathrm{WBC}, 10^{\wedge} 3 / \mu \mathrm{L}$ & $1.089(1.035-1.145)$ & 0.001 \\
\hline Lymphocyte, $10^{\wedge} 3 / \mu \mathrm{L}$ & $0.599(0.390-0.920)$ & 0.019 \\
\hline AST, IU/L & $1.008(1.000-1.015)$ & 0.043 \\
\hline ALT, IU/L & $1.001(0.998-1.004)$ & 0.650 \\
\hline Highest CRP, mg/L & $1.007(1.004-1.011)$ & $<0.001$ \\
\hline Highest LDH, IU/L & $1.001(1.000-1.002)$ & 0.005 \\
\hline Highest creatinine, mg/L & $1.015(0.932-1.104)$ & 0.737 \\
\hline Highest ferritin, ng/mL & $1.001(1.001-1.001)$ & $<0.001$ \\
\hline Highest fibrinogen, mg/dL & $1.000(0.998-1.002)$ & 0.787 \\
\hline \multicolumn{3}{|l|}{ Thorax CT classification } \\
\hline 0 (negative) & 1 & 0.009 \\
\hline 1 (atypical) & $7.880(1.711-34.502)$ & 0.017 \\
\hline 2 (indeterminate) & $6.610(1.425-29.995)$ & \multirow{2}{*}{$<0.001$} \\
\hline 3 (typical) & $9.633(2.511-37.122)$ & \\
\hline \multicolumn{3}{|l|}{ Anticoagulation } \\
\hline $0:$ (no) & 1 & \multirow[t]{2}{*}{0.022} \\
\hline 1: (yes) & $0.336(0.132-0.855)$ & \\
\hline
\end{tabular}

Significant $P$ values are in bold

coronavirus-associated long-term pulmonary dysfunction and overall end-organ damage [24, 25]. In our study, there was no relationship between ACEI usage and mortality; but the mortality rate for ARB users was lower.

Although fever is the most common symptom in the general population (98.0\%); In our study, the most common symptom was "dyspnea" (45.9\%) [26, 27]. Fever response is usually reduced during infection due to decreased immune system response in the elderly. In our study, dyspnea was an important predictor of mortality. Therefore, we can easily say that the prognosis of patients with shortness of breath will be worse. Those with cough, myalgia, or headache symptoms had a lower mortality rate. It is known that cough reflex decreases with aging due to the gradual deterioration in motor functions. Older adults experience clouding of consciousness easily with infection. Therefore, they may not be able to describe the symptoms of headache and myalgia.

In the literature, it has been found that some laboratory parameters such as CRP, ferritin, LDH, D-dimer, AST,
ALT, which determine death, are higher in patients with a poor prognosis $[28,29]$. Similar results were found in our study. High LDH may reflect the degree of pulmonary damage [30]. High D-dimer poses a risk in terms of arterial and venous thromboembolism [31]. In response, anticoagulants have been incorporated into COVID-19 treatment protocols; It is also seen in our study that anticoagulant usage significantly reduced mortality. Again, studies show that severe cases of COVID-19, similar to our research, tend to have higher neutrophil counts and lower lymphocyte counts. [32].

In our study, mortality was high in patients with low firsttime saturation and the lowest $\mathrm{SpO}_{2}$ values. Again, the mortality rate was higher in patients who needed intensive care to follow up and whose vital signs were unstable.

Like other studies, some patients with positive thorax CT findings presented with negative COVID PCR [33]. Some studies have already reported that the sensitivity of PCR is $71 \%$, which is lower than that of thorax CT [34]. Therefore thorax CT is an essential tool for diagnosis and monitoring for COVID-19. [35] In our study, typical, atypical, and indeterminate chest $\mathrm{CT}$ manifestations were associated with death. Based on the data published so far, although there is no evidence to suggest that corticosteroid therapy reduces mortality in COVID-19; some clinical observational studies have shown some benefit in terms of improvements in clinical symptoms and oxygenation [36, 37]. Another study found that the use of dexamethasone in patients hospitalized with Covid-19 resulted in a lower 28-day mortality in patients receiving invasive mechanical ventilation or nasal oxygen, while no significant difference was found in those who did not receive respiratory support [38]. A meta-analysis of clinical trials in critically ill patients with COVID-19 found that systemic corticosteroids reduced 28-day all-cause mortality [39]. In our study, steroid treatment was started in patients with cytokine storm, prominent lung involvement, and desaturated patients 1 week after the diagnosis. It is observed that patients taking steroids die more and more steroids are given in the second 6 months. This result may be due to the fact that patients hospitalized in the second 6 months are more unstable and steroid treatment is used for critically ill patients.

In the second 6 months of the pandemic, stable patients were treated at home and only critical patients were admitted to the hospital. This revealed some differences in mortality, clinical and laboratory findings between hospitalized patients in the first and second 6 months. As shown in Table 4, during the second six-month period, hospitalized patients had lower blood pressure, worse oxygen exchange, worse CT findings, and more need of intensive care. Therefore, in our study, the second 6-month period mortality was higher and clinical and laboratory findings were worse.

In this study, the factors affecting mortality in elderly patients infected with COVID-19 were examined. This 
study had some limitations. First, since it was difficult to reach the patients' full medical history, data were based on the patients' self-reporting; thus, it may lead to recall bias. Second, the number of patients in the three age groups was different. The hospitalization day of the patients may have caused a difference in the results. In addition, unknown duration of the comorbidity was a possible confounding factor. Also viral load and cytokines were not assessed in our study. A screening test for frailty was not performed.

We think that frailty assessment will be an essential parameter in geriatric patients in prospective studies. Although it is not clear yet when the COVID-19 pandemic will end, what is known is the fact that COVID-19 is more serious and deadly in the elderly. For this reason, it is important to clarify the causes of mortality. Elderly patients with COVID-19 should be monitored more closely, and more attention should be paid to factors affecting mortality. Polypharmacy is a geriatric syndrome that should be carefully evaluated. Anticoagulation plays a key role in the treatment of COVID-19. Although the efficacy of vaccines in older adults is not well known, a better preventation has not yet been found. The future of the elderly will be determined by the vaccination of the whole world as soon as possible.

Author contributions We the undersigned declare that this manuscript is original, has not been published before and is not currently being considered for publication elsewhere. We confirm that the manuscript has been read and approved by all named authors and that there are no other persons who satisfied the criteria for authorship but are not listed. We further confirm that the order of authors listed in the manuscript has been approved by all of us. We understand that the Corresponding Author is the sole contact for the Editorial process. He is responsible for communicating with the other authors about progress, submissions of revisions and final approval of proofs Signed by all authors as follows: GUA, BBK, VS, GC, BK, RK, FT, SB, GA, HY and AD. For manuscript titled "Clinical outcomes of geriatric patients with COVID19: review of one-year data".

Funding The authors declare this study to have received no financial support.

\section{Declarations}

Conflict of interest No conflict of interest has been declared by the authors.

Statement of human and animal rights This study was approved by the Ethics Committee of Istanbul University-Cerrahpaşa, Cerrahpaşa Medical Faculty (35115-19.02.2021).

Informed consent An informed consent was obtained from all participants who were given assurances that their data would be treated confidentially.

\section{References}

1. Zheng J (2020) SARS-CoV-2: an emerging coronavirus that causes a global threat. Int J Biol Sci 16:1678-1685. https://doi. org/10.7150/ijbs. 45053

2. Su S, Wong G, Shi W et al (2016) Epidemiology, genetic recombination, and pathogenesis of coronaviruses. Trends Microbiol 24:490-502. https://doi.org/10.1016/j.tim.2016.03.003

3. Dent E, Morley JE, Cruz-Jentoft AJ et al (2019) Physical frailty: ICFSR International clinical practice guidelines for identification and management. J Nutr Health Aging 23:771-787. https://doi. org/10.1007/s12603-019-1273-z

4. Landi F, Barillaro C, Bellieni A et al (2020) The new challenge of geriatrics: saving frail older people from the SARS-CoV-2 pandemic infection. J Nutr Health Aging 24:466-470. https://doi.org/ 10.1007/s12603-020-1356-x

5. Wang L, He W, Yu X et al (2020) Coronavirus disease 2019 in elderly patients: characteristics and prognostic factors based on 4-week follow-up. J Infect 80:639-645. https://doi.org/10.1016/j. jinf.2020.03.019

6. Simpson S, Kay FU, Abbara S et al (2020) Radiological Society of North America Expert Consensus Statement on Reporting Chest CT Findings Related to COVID-19. Endorsed by the Society of Thoracic Radiology, the American College of Radiology, and RSNA-Secondary Publication. J Thorac Imaging 35:219-227. https://doi.org/10.1097/RTI.0000000000000524

7. Kim J, Parish AL (2017) Polypharmacy and medication management in older adults. Nurs Clin North Am 52:457-468. https://doi. org/10.1016/j.cnur.2017.04.007

8. Masnoon N, Shakib S, Kalisch-Ellett L et al (2017) What is polypharmacy? A systematic review of definitions. BMC Geriatr 17:230. https://doi.org/10.1186/s12877-017-0621-2

9. Zhou F, Yu T, Du R et al (2020) Clinical features of patients infected with 2019 novel coronavirus in Wuhan, China. Lancet 395:497-506. https://doi.org/10.1016/S0140-6736(20)30183-5

10. Acar HC, Can G, Karaali R et al (2021) An easy-to-use nomogram for predicting in-hospital mortality risk in COVID-19: a retrospective cohort study in a university hospital. BMC Infect Dis 21:148. https://doi.org/10.1186/s12879-021-05845-x

11. Shahid Z, Kalayanamitra R, McClafferty B et al (2020) COVID-19 and older adults: what we know. J Am Geriatr Soc 68:926-929. https://doi.org/10.1111/jgs.16472

12. Zhang J, Dong X, Cao YY et al (2020) Clinical characteristics of 140 patients infected by SARS-CoV-2 in Wuhan. China Allergy 75:1730-1741. https://doi.org/10.1111/all.14238

13. Sun H, Ning R, Tao Y (2020) Risk factors for mortality in 244 older adults with COVID-19 in Wuhan, China: a retrospective study. J Am Geriatr Soc 68:E19-E23. https://doi.org/10.1111/jgs. 16533

14. CDC COVID-19 Response Team (2020) Severe outcomes among patients with coronavirus disease 2019 (COVID-19)_United States, February 12-March 16, 2020. MMWR Morb Mortal Wkly Rep 69:343-346. https://doi.org/10.15585/mmwr.mm6912e2

15. Wu Z, McGoogan JM (2020) Characteristics of and important lessons from the coronavirus disease 2019 (COVID-19) outbreak in China: summary of a Report of 72314 cases from the Chinese Center for Disease Control and Prevention. J Am Med Assoc 323:1239-1242. https://doi.org/10.1001/jama.2020.2648

16. Yu C, Lei Q, Li W et al (2020) Clinical characteristics, associated factors, and predicting COVID-19 mortality risk: a retrospective study in Wuhan, China. Am J Prev Med 59:168-175. https://doi. org/10.1016/j.amepre.2020.05.002

17. Meng Y, Lu W, Guo E et al (2020) Cancer history is an independent risk factor for mortality in hospitalized COVID-19 patients: 
a propensity score-matched analysis. J Hematol Oncol 13:75. https://doi.org/10.1186/s13045-020-00907-0

18. Liang W, Guan W, Chen R et al (2020) Cancer patients in SARSCoV-2 infection: a nationwide analysis in China. Lancet Oncol 21:335-337. https://doi.org/10.1016/S1470-2045(20)30096-6

19. Xu H, Zhong L, Deng J et al (2020) High expression of ACE2 receptor of 2019-nCoV on the epithelial cells of oral mucosa. Int J Oral Sci 12:8. https://doi.org/10.1038/s41368-020-0074-x

20. Letko M, Marzi A, Munster V (2020) Functional assessment of cell entry and receptor usage for SARS-CoV-2 and other lineage B betacoronaviruses. Nat Microbiol 5:562-569. https://doi.org/ 10.1038/s41564-020-0688-y

21. Zhou P, Yang XL, Wang XG et al (2020) A pneumonia outbreak associated with a new coronavirus of probable bat origin. Nature 579:270-273. https://doi.org/10.1038/s41586-020-2012-7

22. Tikellis C, Thomas MC (2012) Angiotensin-converting enzyme 2 (ACE2) is a key modulator of the renin angiotensin system in health and disease. Int J Pept. https://doi.org/10.1155/2012/ 256294

23. Rathinasabapathy A, Horowitz A, Horton K et al (2018) The selective angiotensin II type 2 receptor agonist, compound 21 , attenuates the progression of lung fibrosis and pulmonary hypertension in an experimental model of bleomycin-induced lung injury. Front Physiol 9:180. https://doi.org/10.3389/fphys.2018. 00180

24. Namsolleck P, Moll GN (2020) Does activation of the protective Renin-Angiotensin System have therapeutic potential in COVID19? Mol Med 26:80. https://doi.org/10.1186/s10020-020-00211-0

25. Muscha Steckelings U, Sumners C (2020) Correcting the imbalanced protective RAS in COVID-19 with angiotensin AT2-receptor agonists. Clin Sci 134:2987-3006. https://doi.org/10.1042/ CS20200922

26. Simonsick EM, Meier HCS, Shaffer NC et al (2016) Basal body temperature as a biomarker of healthy aging. Age (Dordr) 38:445454. https://doi.org/10.1007/s11357-016-9952-8

27. Sun P, Qie S, Liu Z et al (2020) Clinical characteristics of hospitalized patients with SARS-CoV-2 infection: a single arm metaanalysis. J Med Virol 92:612-617. https://doi.org/10.1002/jmv. 25735

28. Wang K, Zuo P, Liu Y et al (2020) Clinical and laboratory predictors of in-hospital mortality in patients with coronavirus disease-2019: a cohort study in Wuhan. China Clin Infect Dis 71:2079-2088. https://doi.org/10.1093/cid/ciaa538

29. Bousquet G, Falgarone G, Deutsch D et al (2020) ADL-dependency, D-Dimers, LDH and absence of anticoagulation are independently associated with one-month mortality in older inpatients with Covid-19. Aging (Albany NY) 12:11306-11313. https://doi. org/10.18632/aging.103583
30. Chiang CH, Shih JF, Su WJ et al (2004) Eight-month prospective study of 14 patients with hospital-acquired severe acute respiratory syndrome. Mayo Clinic Proc 79:1372-1379. https://doi.org/ $10.4065 / 79.11 .1372$

31. Marietta M, Coluccio V, Luppi M (2020) COVID-19, coagulopathy and venous thromboembolism: more questions than answers. Intern Emerg Med 15:1375-1387. https://doi.org/10.1007/ s11739-020-02432-x

32. Qin C, Zhou L, Hu Z et al (2020) Dysregulation of immune response in patients with coronavirus 2019 (COVID-19) in Wuhan, China. Clin Infect Dis 71:762-768. https://doi.org/10. $1093 / \mathrm{cid} / \mathrm{ciaa} 248$

33. Xie X, Zhong Z, Zhao W et al (2020) Chest CT for typical coronavirus disease 2019 (COVID-19) pneumonia: relationship to negative RT-PCR testing. Radiology 296:E41-E45. https://doi. org/10.1148/radiol.2020200343

34. Fang Y, Zhang H, Xie J et al (2020) Sensitivity of chest CT for COVID-19: comparison to RT-PCR. Radiology 296:E115-E117. https://doi.org/10.1148/radiol.2020200432

35. Wang Y, Kang H, Liu X et al (2020) Combination of RT-qPCR testing and clinical features for diagnosis of COVID-19 facilitates management of SARS-CoV-2 outbreak. J Med Virol 92:538-539. https://doi.org/10.1002/jmv.25721

36. Zhou W, Liu Y, Tian D et al (2020) Potential benefits of precise corticosteroids therapy for severe 2019-nCoV pneumonia. Signal Transduct Target Ther 5:18. https://doi.org/10.1038/ s41392-020-0127-9

37. Wang Y, Jiang W, He Q et al (2020) A retrospective cohort study of methylprednisolone therapy in severe patients with COVID-19 pneumonia. Signal Transduct Target Ther 5:57. https://doi.org/10. 1038/s41392-020-0158-2

38. RECOVERY Collaborative Group, Horby P, Lim WS et al (2021) Dexamethasone in hospitalized patients with Covid-19. N Engl J Med 384:693-704. https://doi.org/10.1056/NEJMoa2021436

39. WHO Rapid Evidence Appraisal for COVID-19 Therapies (REACT) Working Group, Sterne JAC, Murthy S et al (2020) Association between administration of systemic corticosteroids and mortality among critically ill patients with COVID-19: a meta-analysis. JAMA 324:1330-1341. https://doi.org/10.1001/ jama.2020.17023

Publisher's Note Springer Nature remains neutral with regard to jurisdictional claims in published maps and institutional affiliations. 